\title{
Knowledge of Romani language grammar
}

\author{
Hristo Kyuchukov ${ }^{\text {a*}}$, Milan Samko ${ }^{\mathrm{b}}$, Dagmar Kopcanova ${ }^{\mathrm{c}}$ \\ a University of Silesia, Katowice, Poland \\ ${ }^{\mathrm{b}}$ Constantine the Philosopher University, Nitra, Slovakia \\ ${ }^{c}$ Research Institute of Child Psychology and Pathopsychology, Bratislava, Slovakia \\ *Corresponding author. E-mail: hkyuchukov@gmail.com
}

Objective. The paper examines knowledge of Romani grammatical categories among Roma children from Bulgaria and Slovakia between the ages of 3 and 6 years.

Design. Roma children from Bulgaria and from Slovakia completed a psycholinguistic test in the Romani language. The test was developed for the first time in Europe to measure an individual's knowledge of the Romani language (comprehension and production). The newly developed test measured comprehension of categories such as wh questions, wh complements, passive verbs and possessiveness.

Results and discussion. The children's knowledge is associated with two theories: the ecological theory of Ogbu (1978) and the integrative theory of child development (García Coll et al. 1996). Ogbu's theory stresses the importance of children's home culture in their development. According to the theory of García Coll and her collaborators, the family's home environment and SES are important predictors of language development.

Keywords: Roma children, language assessment test, integrative theory

\section{Introduction}

Research shows that all normally developing children follow the same "paths" in their language development. Children develop the sound system first, then vocabulary and syntax, and later, the ability to narrate (Tomasello, 2003; Roskos and Neuman, 2005; Neuman and Marulis, 2010). Roma children are no exception in this process of language development. The only difference is that Roma parents use different strategies and approaches for language development that are partially from the Roma culture (e.g., fairytales, folk songs, teasing, and language games). In Roma communities, everyone is free to communicate and play with children. Within extended families, Roma children are exposed to different registers when speaking with parents, adults and siblings (Kyuchukov, 2014; Kyuchukov, Kaleja \& Samko, 2016).

In some European countries, Roma children are still tested with IQ tests, although in the U.S. and some European countries, the use of IQ tests is forbidden. 
Bafekr (1999) studied "two culturally distinct groups: Poles and Romanian Gypsies" using "projective tests and intelligence tests as an aid to understand many difficult situations." According to the author, Roma children are often absent from school due to their culture because the knowledge acquired at school "does not conform to the values of Gypsy culture, particularly not at the cognitive and semantic levels" (p. 300). Bafekr (1999: 301) also notes,

"On the standardized intelligence tests the [Roma] children scored far below average. At the same time, however, their 'practical' intelligence appears to be much higher than many children at the same age. Children as young as eight, for example, are expected to find their way around the city, survive in any situation, and give the impression of the independence. This finding is confirmed in virtually all the literature describing the educational problems of Gypsy children... If the attitude towards education in Gypsy culture is considered along with their view of the world (which is pre-operational at the cognitive level), then different test results are all too understandable since they are based on 'Western' standards. At a minimum, then, we should stop assessing the intelligence of Gypsy children against Western standards using Western measures. Perhaps an attempt should be made to educate them in a way that guarantees a minimum of educational and cultural compliance between the two cultures."

Although Bafekr makes what can be interpreted as racist comments about the Roma culture and schooling, ultimately, he suggests that Roma children should not be measured by Western IQ tests, even though researchers continue to use them. However, only five years later, when researching Czech and Slovak Roma children, Bakalar (2004:291) noted,

"Several studies in central Europe have shown that Gypsies tend to score lower on IQ tests. This has frequently been explained as the results of (a) the poor environmental conditions in which Gypsy families live and (b) language difficulties, because a number of Gypsies speak their own language and not that of the majority population. It is probable that the environment in which Gypsies typically live does not foster the development of intellectual abilities and social mobility. However, the pervasive social failure of Gypsies in all studied societies raises the question of whether their intellectual deficit is due to biological/genetic causes as well as environmental differences." [our italics]

Bakalar argues that one problem Roma children face is they speak their mother tongue, which causes them to score low on IQ tests. However, strangely enough, the author does not question the cultural appropriateness of the IQ test. He clearly thinks that "Western" IQ tests are suitable for all cultures and are not culturally biased. The basically racist comment on the "intellectual deficit" of Roma children is unacceptable in science and reminiscent of the style of Nazi discourse during WWII.

Another study by Kertesi and Kezdi (2011) compares ethnic Hungarian children from mainstream schools and Roma children from special schools and discovers that the test-score gap between Roma and non-Roma is similar to the black/ white racial disparities in the United States during the 1980s. The authors conclude that in Hungary, education and poverty play an overwhelming role in the significant score gaps in such tests. 
Rushton, Cvorovic and Bons (2007) and Cvorovic (2014) focus on the IQ test performance of Serbian Roma. The first study tested Roma with Raven's Standard Progressive Matrices (SPM), measuring "the ability to identify relationships," "analogical thinking" and the ability to "think clearly". Another test used in the study was the Colored Progressive Matrices (CPM). The Roma averaged very low scores on all tests. The authors found that the SPM and CPM percentile points converted to an IQ equivalent of 70. Although the authors note that the tests used may not be culturally appropriate for the Roma culture, they conclude that "the Roma children grow up in culturally disadvantaged conditions [...] [they] are not as exposed to the intellectual stimulation and test taking attitudes typically associated with high test scores" (Rushton, Cvorovic and Bons, 2007:10).

Cvorovic's (2014) book, The Roma: A Balkan underclass, explains that two-thirds of the child subjects had been diagnosed with "light mental retardation." The author collated published IQ tests results, mostly involving Wechsler tests of reasonably sized samples, with local populations as control groups. Adult Roma were shown to have intelligence scores very similar to South Asians, with average adults, in a wide variety of samples, demonstrating IQs in the 70 range. According to the author, "the poor scholarship of the children seems to be due to a mixture of low ability and a strong belief that education beyond primary school is of no interest or benefit." Unfortunately, this study is replete with prejudices, stereotypes and racist statements about Roma. From reading the book, one can conclude the Roma are in this situation because they have clung to their culture since they arrived in Europe eight centuries ago, and in all this time, living in Europe has had almost no impact on them.

In her dissertation from 1943, Eva Justin conducted "psychological" research to measure the intelligence of Roma children in Nazi Germany. Her findings suggest that as a result of their low IQs, "Roma children do not have abstract thinking...; they have problems with concentration and attention...; do not have the discipline of German children...; the boys are genetically predisposed to be criminals;... and the girls are genetically predisposed to be prostitutes". The recommendation drawn from her "research" is that Roma should be sterilized "to avoid the reproduction of asocial Gypsies who are not willing to integrate into German society." Forty-one Roma children from Justin's study were sent to Auschwitz, where some were objects of the medical "research" conducted by Dr. Josef Mengele and others were killed in gas chambers. Only two children involved in Justin's study survived the concentration camp.

Comparing the publications on Roma intelligence from contemporary and modern European authors with Justin's 1943 dissertation, for all these authors, the main problem appears to be the fact that the children know their mother tongue and culture. This is, in these authors' view, an obstacle to integration into the majority societies. The authors seem to be unfamiliar with existing theories and publications regarding the importance and use of one's mother tongue and culture in the cognitive development of minority children.

In this article, we partially adapt the model for the study of child development, which was developed by Garcia Coll et al. (1996) in the U.S. and addresses children of color. The authors present an integrative model of child development, drawing on Parsons' (1940) social stratification theory and emphasizing the influence of racism, prejudice, discrimination, oppression, and segregation on the development of minority families and children (Garcia Coll et al., 1996). 
According to Bronfenbrenner $(1979,1986)$, the family's interaction with other groups and institutions influences the way children adapt to non-familial environments such as school. Influential factors in children's success at school are the parents' level of education, employment, the parent-child relationship, home environment, and resources available inside and outside the home. Ogbu (1978, 1981, 1988) [based on Han, 2006] adapts Bronfenbrenner's theory and applies it to emigrant children's families with an emphasis on the importance of the culture. García Coll et al. (1996) stress the importance of the surrounding environment on children's behavioral, emotional, and cognitive development. The neighborhood and school environment either promote or inhibit minority children's development (Han, 2006). According to Han (2006), the social position of a group of people and the racism and segregation directed against them are important factors in the education process. García Coll et al. (1996) do not underestimate the role of culture in the learning process of minority children. Children's extended families, community and friends help them learn new things in everyday life. Han (2006) stresses,

Additionally, child/parent/family characteristics, home environment and parental educational practices (e.g., learning activities at home, participation in extracurricular activities and school events), and school (e.g., student composition and average academic performance, parental involvement, school safety) and neighborhood (e.g., residential neighborhood quality) environments are considered possible mediating factors for any such associations (p. 288).

Forget-Dubois et al. (2009) studied the effect of home environment quality on a child's school readiness. The authors consider SES an indicator of the general home environment quality. They argue that the features of the home environment are significantly predictive of later language skills; SES and maternal speech are very important for vocabulary development; and language skills and school readiness are correlated. Children with low SES but higher language competence evince a good level of school readiness. The relationship between language development and school readiness is not only a predictor of school achievement but also a measure of school readiness.

Rydland (2009) conducted research among bilingual Turkish children from Norway and investigated their pretended play. Through pretended play, the children develop complex language skills and narrativity. Their highly developed oral skills show the children's pragmatic language competence in their mother tongue, which is important for second-language acquisition.

The analysis of the literature shows that Roma children's IQ tests "prove" that Roma children have low scores on IQ tests. However, there are also theories and publications related to minority/migrant children that indicate that the home environment, language and culture play important roles in children's development.

The aim of this article is to present results from international research showing the level of knowledge of Romani as a mother tongue among Roma children in Bulgaria and Slovakia. With this study, we attempt to answer the following research question:

Which grammatical categories do normally developing Roma children know in their mother tongue at the ages of three to six years? 


\section{Method}

The research included 60 Roma children between three and six years old: 30 children from Bulgaria and 30 children from Slovakia. The children were selected randomly. They were grouped in three age groups:

- 1 gr. 10 children $3.0-3.11$ years old

- 2 gr. 10 children $4.0-4.11$ years old

- 3 gr. 10 children $5.0-6.0$ years old

All of the children were tested in their mother tongues, which were varieties of the Romani language. Roma in Slovakia and Roma in Bulgaria speak different dialects, but the language is the same. The children were tested in community centers by speakers of the two particular dialects. They did not attend kindergarten, and most of the knowledge they acquired about the world was obtained through communication with their family members.

Three picture tests were used to test the language knowledge of Roma children in their mother tongue:

Test 1: Wh- questions (Who eats what?) -8 items - production test. The children were shown eight pictures with different actions completed by the protagonists and asked questions about the actions. In some languages, when there are two wh words at the beginning of the sentence, the first wh word is answered, whereas in other languages, the second wh word is answered. For the children, the expectation is that they will answer both wh words in each sentence.

Test 2: Passive verbs (The dog was kicked by the horse) - 16 items - comprehension test with multiple choice. The test measured the children's knowledge of passive statements. Children usually understand sentences such as, The dog kicks the horse. However, they find it more difficult to understand sentences such as, The horse was kicked by the dog.

Test 3: Possessiveness (The horse has a balloon. This is not your balloon. This is the...) -26 items - production test. The test is based on Berko's Wug test (1958). The children must fill in the missing word verbally, which, in this case, includes the possessive endings in Romani for masculine and feminine and for singular and plural with both known and novel objects.

The tests were adapted to the local dialects spoken by Roma from the two communities in Bulgaria and in Slovakia.

Our hypotheses are as follows:

H1: The SES of the Roma families give an influence the language development of their children.

\section{Results}

The findings from the first test, $\mathrm{Wh}$ - questions, show that between the age groups, there were statistically significant differences. The first age group from both countries (3-4 years old) showed lower results in comparison to the third age group (5-6 years old). Figure 1 shows the total score of the first test as a function of age group. 




Figure 1. Total scores on Wh-questions test as a function of age group

The impact of the factor of age group on the total scores of Wh questions test as a dependent variable is statistically significant $(\mathrm{F}=12,94 ; \mathrm{p}<0,0001)$. The size effect is large $\left(\eta^{2}=0,34\right)$. The post hoc tests show that between all groups, there are statistically significant differences. Comparing the results of the children between the two countries, one can see that the Roma children from Bulgaria have higher results than the Roma children from Slovakia have.

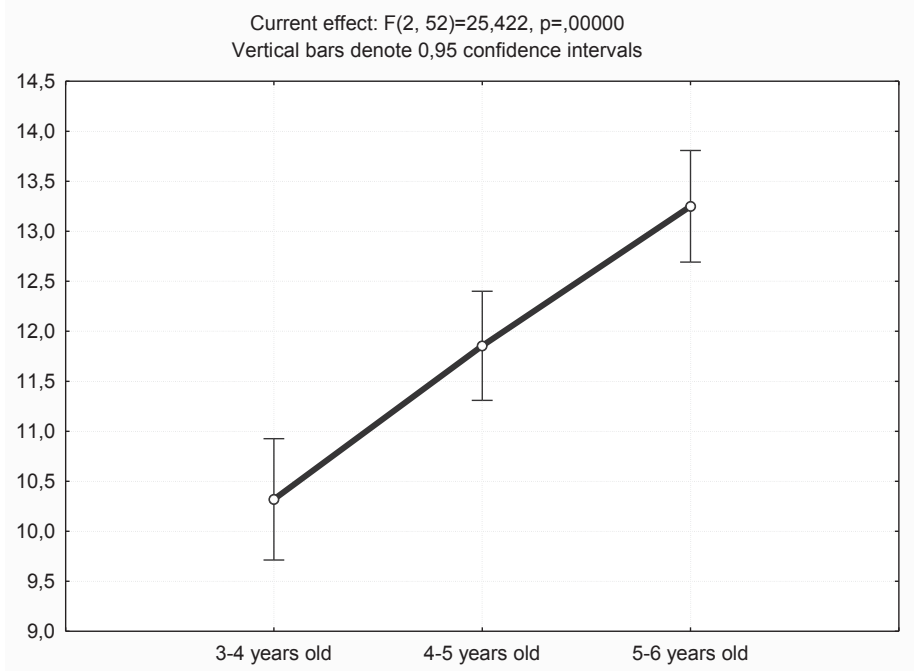

Figure 2. Total scores on passive verbs test as a function of age group

The impact of the factor of country on the total scores of the Wh questions test as a dependent variable is statistically significant $(\mathrm{F}=20,28 ; \mathrm{p}<0,0001)$. The size effect is medium $\left(\eta^{2}=0,28\right)$. The Roma children from Bulgaria performed much better on this test than the Slovak Roma children did. 
In the performance of the second test on passive verbs, the age groups again show significant differences. Figure 2 indicates that older children from both countries understand and complete the tasks much better than the younger children do. The results are plotted in Figure 2.

The impact of the factor of age group on the total scores on the passive verbs test as a dependent variable is statistically significant $(\mathrm{F}=25.42 ; \mathrm{p}<.0000)$. The size effect is large $\left(\eta^{2}=0.49\right)$. The post hoc analyses show that the differences between all three groups are statistically significant. Comparing the children from the two countries, one can see again that the Bulgarian Roma children perform much better on this test. The impact of the factor of country on the total scores for the passive verbs test as a dependent variable is statistically significant $(\mathrm{F}=35.45 ; \mathrm{p}<.0000)$. The size effect is large $\left(\eta^{2}=0.41\right)$. Again, the Bulgarian children performed much better than the Slovak children did.

How did the children perform in the third test related to the possessive? The results are given in Figure 3.

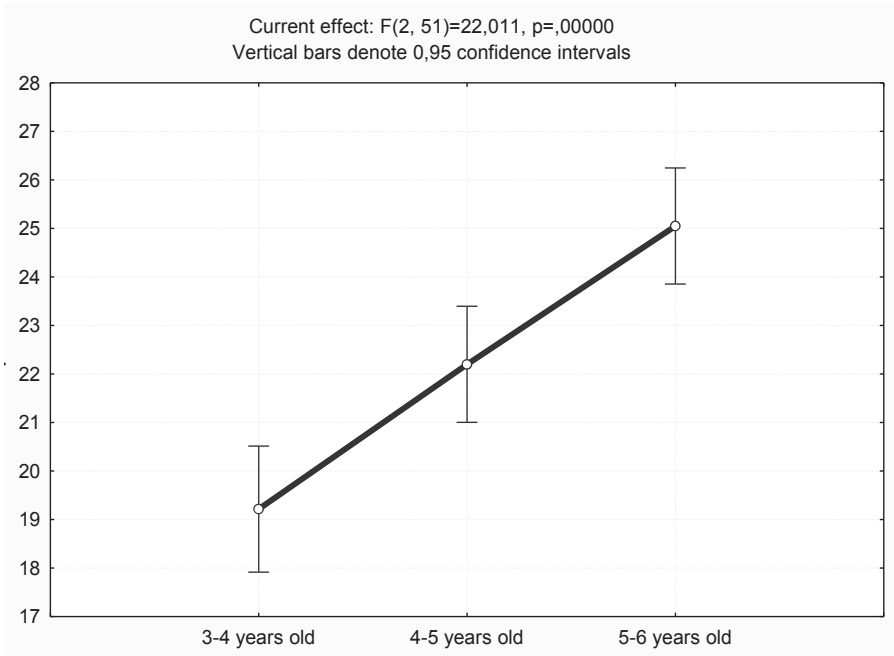

Figure 3. Total scores on possessiveness test as a function of age group

The impact of the factor of age group on the total scores on the possessiveness test as a dependent variable is statistically significant $(F=22.01 ; \mathrm{p}<.0000)$. Size effect is large $\left(\eta^{2}=.46\right)$. Again, the older children from both countries performed much better than the younger children did. The post hoc analyses show that the differences between the three groups are statistically significant. How did the children perform on this test by country? The impact of the factor of country on the total scores on the possessiveness test as a dependent variable is statistically significant $(\mathrm{F}=39.86 ; \mathrm{p}<.0000)$. The size effect is large $\left(\eta^{2}=.44\right)$. Again, the Bulgarian Roma children performed much better than the Slovak Roma children did.

Figure 4 shows the total scores on the possessiveness test as a function of interaction between two factors: age group and country.

Figure 4 clearly shows that all age groups from Bulgaria perform much better on the possessiveness test than do the Roma children from Slovakia. The impact of the interaction between the factors of age group and country on the total scores on 
the possessiveness test as a dependent variable is statistically significant $(\mathrm{F}=6,46$; $p<0,01)$. The size effect is medium $\left(\eta^{2}=0,20\right)$. The post hoc analyses show the differences between groups by country. One can see that between the first and second groups from both countries, the differences are statistically significant; however, between the third age groups, there are no statistically significant differences.

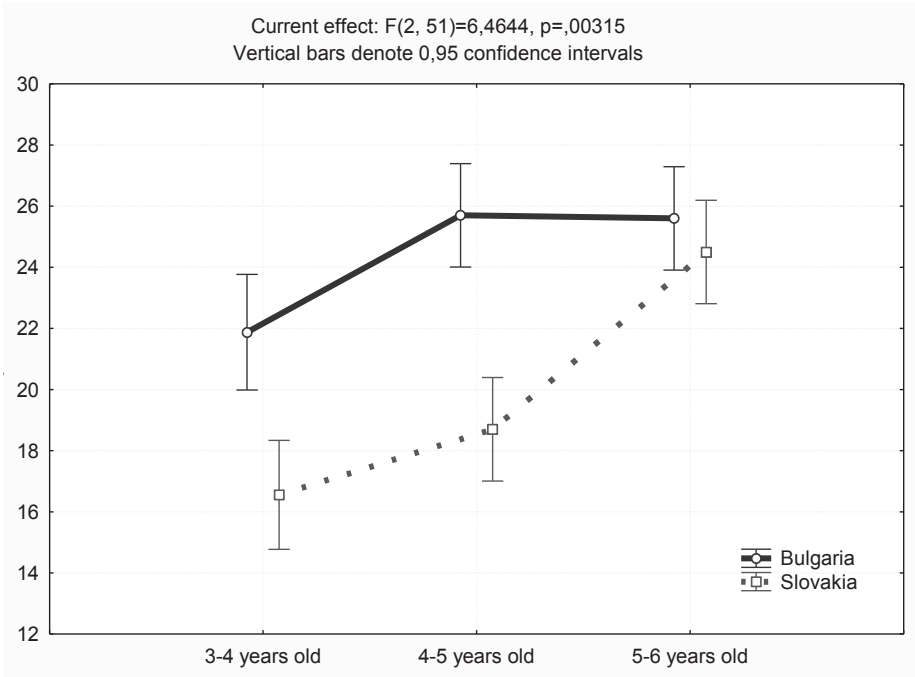

Figure 4. Total scores on possessiveness test as a function of interaction between factors age group and country

\section{Discussion and Conclusion}

Returning to the hypotheses of the study, it seems that our first hypothesis is confirmed. We see that the SES of the families influences the language development of the children and their school readiness, as stated by García Coll et al. (1996). Although the Roma children from Bulgaria live in a ghetto-like settlement, they live in much better conditions than the Roma children from Slovakia. It seems that the Slovak Roma children grow up in highly deprived conditions (in some cases, very similar to the conditions prevailing in some African countries) and lack access to toys, books, television, the Internet and other facilities. Growing up stigmatized as Roma, with all the negative stereotypes and prejudices in the society against Roma, confirms the integrative theory of García Coll and her collaborators that a society's negative phenomena and attitudes toward minority groups, such as racism and discrimination, influence the development of families and their children. In this case, the Roma children do not have the necessary readiness for school education because the isolation and segregation in which they live and grow up do not provide them a natural possibility to become socialized in society, as is the typical case for children from the majority population. Their socialization occurs only in the Roma community and follows the community's norms. They do not know how to behave outside the Roma community or in institutional settings such as school.

Unlike the Slovak Roma children, the Bulgarian children have much better conditions and more contacts with the majority society because although they live 
in a ghetto-like settlement, they do not live far from the town. Moreover, most of the Slovak Roma children have much better conditions at home. Additionally, the Protestant church plays an important role in their lives. Organized religious cultural activities, such as summer schools, Sunday schools and excursions, bring together Roma and non-Roma. From early ages, the children benefit from these activities because they are introduced to different behaviors and different types of socialization. Therefore, there is an ensemble of factors that influence the lives of Bulgarian Roma children in a positive way, which helps to shape an ecology of positive development for them. As a result, Roma children from Bulgaria have better school readiness, although they do not attend kindergarten before entering first grade.

Romani language, which is mainly an oral language, is learned by the children from oral communication and the rich folkloristic culture, including songs, fairy tales, teasing, jokes and other genres of folklore. It seems that the complex language development of Roma children cannot be achieved until they are five or six years old. Even when they do not attend kindergarten and do not have good conditions at home, between the ages of five and six years, children learn the most complex grammatical structures, as shown by the test for possessiveness. The children between five and six years old from Bulgaria and Slovakia achieved the same level of complex grammatical knowledge based on their performance on the possessiveness test. This can be considered an indicator of school readiness. The research findings with Roma children are contrary to the claims of Bakalar (2007) and Cvorovic (2014), which identified the problem of Roma children's integration as their knowledge of the Romani language as a mother tongue. Although the research is limited, the results from this study show that Roma children should be tested with culturally appropriate tests and in their mother tongue.

\section{Acknowledgments}

Part of the research in this paper was financially supported by the project VEGA 1/0845/15 Jazyková kompetencia rómskych žiakov v prvom ročníku školskej dochádzky and the project VEGA 1/0206/13 Percipovaná sociálnaopora a spokojnost' so sociálnou sietou u obyvatelov rómskych osídlení.

\section{References}

Bafekr, S. (1999). Schools and their undocumented Polish and "Romany Gypsy" pupils. International Journal of Educational Research, 31, 295-302. doi: 10.1016/S0883-0355(99)00007-5

Bakalar, P. (2004). The IQ of Gypsies in Central Europe. The Mankind Quarterly, XLIV(3-4), 291-300.

Berko, J. (1958). The child's learning of English morphology. Word, 14, 150-177. doi: 10.1080/00437956.1958.11659661

Bronfenbrenner, U. (1979). The ecology of human development: Experiments by nature and design. Cambridge, MA: Harvard University Press.

Bronfenbrenner, U. (1986). Ecology of the family as a context for human development: Research perspectives. Developmental Psychology, 22, 723-742. doi: 10.1037/0012-1649.22.6.723

Cvorovic, J. (2014). The Roma: A Balkan underclass. Ulster: Ulster Institute for Social Research. 
Forget-Dubois, N., Lemelin, J.-P., Perusse, D., Tremblay, R. E., \& Boivin, M. (2009). Early child language mediates the relation between home environment and school readiness. Child Development, 80(3), 736-749. doi: 10.1111/j.1467-8624.2009.01294.x

García Coll, C., Lamberty, G., Jenkins, R., McAdoo, H. P., Crnic, K., Wasik, B. H., \& García, H. V. (1996)., An integrative model for the study of developmental competencies in minority children. Child Development, 67(5), 1891-1914. doi: 10.2307/1131600

Han, W.-J. (2006). Academic achievements of children in immigrant families. Educational Research and Review, 1(8), 286-318.

Kezdi, G., \& Kertesi, G. (2011). The Roma/non-Roma test score gap in Hungary. American Economic Review, 101(3), 519-525. 10.1257/aer.101.3.519

Kyuchukov, H. (2014). Acquisition of Romani in a bilingual context. Psychology of Language and Communication, 18(3), 211-225. doi: 10.2478/plc-2014-0015

Kyuchukov, H., Kaleja, M., \& Samko, M. (2016). Roma parents as educators of their children. Intecultural Education, 26(5), 444-448.

Neuman, S., \& Marulis, L. M. (2010). The effects of vocabulary intervention on young children's word learning: A meta-analysis. Review of Educational Research, 80(3), 300-335. doi: $10.3102 / 0034654310377087$

Ogbu, J. U. (1978). Minority education and caste: The American system in cross-cultural perspective. New York: Academic Press.

Parsons, T. (1940). An analytical approach to the theory of social stratification. American Journal of Sociology, 45(6), 841-862. 10.1086/218489

Roskos, K., \& Neuman, S. (2005). The state of pre-kindergartens standard. Early Childhood Research Quarterly, 20, 125-145. doi: 10.1016/j.ecresq.2005.04.010

Rushton, J. P., Cvorovic, J., \& Bons, T. A. (2007) General mental ability in South Asians: Data from three Roma (Gypsy) communities in Serbia. Intelligence, 35(1), 1-12. doi: 10.1016/j. intell.2006.09.002

Rydland, V. (2009) "Whow-when I was going to pretend drinking it tasted coke for real!" Second-language learners' out-of-frame talk in peer pretend play: A developmental study from preschool to first grade. European Journal of Developmental Psychology, 6(2), 190-222. doi: $10.1080 / 17405620601016934$

Tomasello, M. (2003). Constructing a language: A usage-based theory of language acquisition. Cambridge, MA: Harvard University Press.

Original manuscript received October 10, 2016

Revised manuscript accepted December 06, 2016

First published online November 30, 2017 